\title{
Harmony Drivers: No Disagreement Allowed
}

\author{
DOUGLAS PULLEYBLANK \\ University of British Columbia
}

\section{Introduction}

'Harmony' is a widely attested pattern in natural language, a configuration where within some domain all eligible anchors for some feature bear the same feature value. Typically, a harmony system exhibits a choice between two feature values. Either all anchors within some domain $\mathrm{D}$ bear the feature value $\mathrm{F}$ or all anchors within D bear the opposite value G. Depending on the theory of features and harmony, both harmonic values may be overtly specified or one may be indicated by the absence of featural specification.

Within derivational autosegmental theory (Clements 1981, etc.), harmony was generally achieved by requiring (a) that lexical representations choose between specifications of either $F$ or $G / \emptyset$, and (b) that any lexically specified value be realized throughout domain $\mathrm{D}$ via a harmonic rule of spreading. A fundamental distinction was posited between assimilation/harmony and processes such as dissimilation and polarity. Where harmony was analyzed as a type of assimilation (and assimilation was by spreading), dissimilation and polarity were the result of the OCP (McCarthy 1986, etc.), typically resulting from delinking/deletion plus redundancy. Hence assimilation/harmony and dissimilation/polarity were opposites, accounted for by different mechanisms.

With the advent of Optimality Theory (Prince \& Smolensky 1993), the consensus on the mechanism for deriving harmony has disappeared, with very little agreement in the literature as to the formal analysis of harmony. The following constitutes a sample of the constraint types proposed to drive harmony. ${ }^{1}$ In a large body of work (Kirchner 1993, Akinlabi 1996, etc.), it has been suggested that alignment constraints can be applied to features, producing harmony by requiring that some harmonic feature be aligned with the left and right edges of a phonologically or morphologically defined domain: Align(PCat,

\footnotetext{
${ }^{1}$ Numerous issues in the analysis of harmony are not addressed in this paper, for example, how to characterize the eligible targets and the eligible sources for harmony, how to characterize possible blocking segments and possible transparent segments, how to achieve directionality in harmonic patterns. For formal definitions of the constraints mentioned here, see the cited references.
} 
$\mathrm{L} / \mathrm{R} ; \mathrm{MCat} / \mathrm{PCat}, \mathrm{L} / \mathrm{R})$. A related variant of this approach is optimal domains theory (Cole \& Kisseberth 1994, etc.). This approach elevates the formal status of harmonic domains, establishing abstract harmonic domains via alignment and requiring that every anchor within such a domain be affiliated with the harmonic feature. While alignment-based accounts provide a direct analog of directionality, agreement approaches (Baković 2000 , etc.) are inherently directionless, requiring that adjacent segments within some domain have the same value for the harmonic feature. It is quite possible, however, to posit constraints comparable to agreement constraints but with directionality directly encoded. Spread constraints (Walker 1998 , etc.) do exactly this: Spread-L/R([F], D). A rather different approach to encoding harmony has been proposed in work on featural prohibitions and positional faithfulness (Beckman 1995, etc.). By ranking general prohibitions on a harmonic feature above faithfulness $\left({ }^{*}+\mathrm{F}>>*^{*} \mathrm{~F}>>\right.$ IDENT[F]), a general pattern is obtained where only one feature value is tolerated (i.e. $-F$ ). By also ranking a positional faithfulness constraint (e.g. IDENT $\sigma_{1}[\mathrm{~F}]$ ) above the prohibition on $+\mathrm{F}$, harmony is achieved. The last harmony driver to be mentioned was sketched in Smolensky (1993). Smolensky notes that harmony can be achieved by prohibiting disharmony. That is, a sequence of opposite values for some harmonic feature can be prohibited $\left({ }^{*} \mathrm{~F} \mathrm{G}\right)$, with the result that segment sequences must have the same value for the harmonic feature.

This multiplicity of harmony drivers raises interesting questions concerning the properties and learnability of harmony systems. If multiple drivers are possible, then there will be a significant degree of indeterminacy in the analysis of harmony. In this regard, note that several of the approaches to harmony described briefly above involve formal properties of a stipulatory nature. For example, the optimal domains approach requires the postulation of abstract featural domains, while the alignment approach requires equating featural domains with prosodic or morphosyntactic domains, requiring that the 'edges' of featural spans be aligned with such domains. In general, one must ask the question of why such constraints should exist. Why is it desirable to have one feature agreeing with another, or to have one feature spread throughout some domain? To what extent does the functional motivation for such a constraint relate to the constraint's formulation?

In exploring here the option of deriving harmony by prohibiting feature disharmony, the functional motivation is that the resetting of articulatory targets costs the grammar. That is, inertia is claimed to be the central functional principle, with changes of articulatory setting prohibited: *ATR RTR, *RTR ATR; *NASAL ORAL, *ORAL NASAL. Several arguments support such an account of harmony (see also Hansson 2002). The no-disagreement account permits the unification of the driver for harmony with the Obligatory Contour Principle, providing a unified account of vowel harmony and consonant harmony. ${ }^{2}$ Both opacity and

\footnotetext{
${ }^{2}$ Note, however, Hansson's (2001) arguments for distinguishing the two harmony types. If the unified approach to the two harmony types is correct, the differences discussed by Hansson must be attributed to properties other than the harmony driver.
} 


\section{Harmony Drivers: No Disagreement Allowed}

transparency are accounted for, as are patterns of edge-conditioned harmony where eligible undergoers of harmony behave as transparent because they are medial. Cases of incomplete harmony can be accounted for, where target features do not match source features. Before turning to the phonological arguments in favor of no-disagreement, I begin by illustrating the basic mechanisms involved.

\section{Let's not disagree: the basic harmonic effect}

The simplest harmony system requires agreement for the harmonic feature within a domain such as the word. Consider the tongue root harmony system in a language like Degema (Elugbe 1984, Kari 1995, 1997, Pulleyblank et al 1995). This language exhibits a basic 5-vowel system cross-cut by a tongue root distinction. The ten resulting vowels are illustrated in (1), in forms that show the basic harmonic imperative with alternating prefixes and suffixes.
(1) a. Advanced: [i u e o e]
[i] u-bí-ā
state of being black
b. Retracted: $\left[\begin{array}{lllll}1 & \cup & \varepsilon & 0\end{array}\right]$
[u] u-pú-ว̄m
closing
[r] á-kĩ
[v] v-fú-ā
[e] u-dér-ə̄m
cooking
[o] i-sór-̄̄

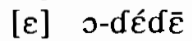
pot
[o] u-bóm-ām
state of being white
[ə] o-gədəgá mighty
[a] o-kpakıraká tough

Roots may be either advanced (1a) or retracted (1b); the tongue root value of an affix is the same as the root to which it is attached.

To achieve harmony, prohibitions on sequences of vowels with different values for the tongue root feature mush outrank faithfulness conditions.

(2)* $\underline{\text { ATR-C }} \mathrm{C}_{0}$-RTR: Ignoring consonants, an ATR segment may not be immediately followed by RTR. ${ }^{3}$

*RTR-C $\mathrm{C}_{0}$ - $\underline{\mathrm{ATR}}$ : Ignoring consonants, an ATR segment may not be immediately preceded by ATR.

I assume a correspondence approach to faithfulness (McCarthy \& Prince 1995) with featural values ensured by 'MAX/DEP FEATURE' and 'MAX/DEP PATH' constraints (Pulleyblank 1996, etc.). ${ }^{4}$ MAX/DEP FEATURE constraints are instantiations of the schema in (3), where F-elements range over features and nodes such as $\{$ ATR, RTR , .. $\}$ and domains include $\{$ Root, Word, ... $\}$.

(3) $[\text { MAXG }]_{D}$ : Within domain $D$, an F-element $G$ in the input must correspond to an F-element $\mathrm{G}$ in the output.

\footnotetext{
${ }^{3}$ Violations are assessed by universally quantifying over one of the members of the sequential constraint, in this case, ATR. That is, in this case one violation is assigned per advanced segment violating the constraint. The ATR-orientation is indicated in the constraint name by underlining.

${ }^{4}$ The basic arguments concerning a no-disagreement approach to harmony could also be achieved with segment-based MAX/DEP in combination with 'IDENT'. Violations would be assessed differently but the optimal candidates would be the same for the cases under consideration.
} 
To achieve root control harmony, as seen in Degema, the harmonic constraints must outrank the faithfulness constraints, and within the faithfulness class, root domain constraints must outrank word domain constraints: * ${ }^{*}$ ATR- $\mathrm{C}_{0}-\mathrm{RTR}$, ${ }^{*} \mathrm{RTR}$ -

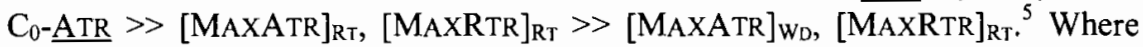
the distinction is not relevant, I will abbreviate [MAXATR $]_{\text {Roor }}$ and [MAXRTR $]_{\text {Root }}$ as '[MAX $]_{\text {ROOT', }}$, and [MAXATR $]_{\text {WORD }}$ and [MAXRTR $]_{\text {WORD }}$ as '[MAX $]_{\text {WORD'. }}$ '.

Consider a case where the root vowel is advanced. Root faithfulness ensures that advancement is preserved (ruling out (4e)); the prohibitions on disagreeing tongue root sequences rule out any candidate with retracted vowels ( $4 \mathrm{~b}-\mathrm{d})$.

\begin{tabular}{|c|c|c|c|c|c|}
\hline (4) & /U-[der]-Am/ & ${ }^{*}$ ATR-C $C_{0}-\mathrm{RTR}$ & ${ }^{*} \mathrm{RTR}-\mathrm{C}_{0}-\mathrm{ATR}$ & {$[\mathrm{MAX}]_{\mathrm{ROOI}}$} & {$[\mathrm{MAX}]_{\text {WORD }}$} \\
\hline a. & [uderəm] & & & & \\
\hline b. & [uderam] & $* !$ & & & \\
\hline c. & [uderəm] & & $* !$ & & \\
\hline d. & [uderam] & *! & $* !$ & & \\
\hline e. & [uderam] & & & *! & * \\
\hline
\end{tabular}

Similar considerations ensure that all vowels are retracted if the root is retracted.

The basic exigencies of harmony are straightforwardly captured by positing constraints prohibiting featural disagreement. If features cannot disagree, and if the prohibition on disagreement outranks faithfulness, the result is a span with a uniform featural specification. ${ }^{6}$

\section{The formal basis for no-disagreement constraints}

Analyzing harmony through no-disagreement constraints permits the unification of harmony with the Obligatory Contour Principle ('OCP'). In essence, the OCP can be analyzed as a sub-case of a general prohibition on sequences of elements. Consider the formulation of the Generalized OCP in Suzuki (1998):

(5) Generalized $O C P:{ }^{*} \mathrm{X} \ldots \mathrm{X}$ : A sequence of $\mathrm{X}$ is prohibited

Proximity: The closer the elements are the stronger the interaction.

Adjacency: ${ }^{*} \mathrm{X} \ldots \mathrm{X}=\left\{{ }^{*} \mathrm{XX} \gg>^{*} \mathrm{X}-\mathrm{C}_{0}-\mathrm{X} \gg{ }^{*} \mathrm{X}-\mu-\mathrm{X} \gg, \ldots>{ }^{*} \mathrm{X}-\infty-\mathrm{X}\right\}$

Similarity: The more similar the elements are the stronger the interaction.

\footnotetext{
${ }^{5}$ In line with work such as Mohanan 1993, Archangeli \& Pulleyblank to appear, I assume that constraints hold more strongly of small domains than larger domains, deriving the observed root/affix asymmetry. Root control could also be achieved by assuming a constraint on root faithfulness that would outrank a constraint on affix faithfulness (McCarthy \& Prince 1995).

${ }^{6}$ For reasons of space, I do not examine issues here concerning 'Richness of the Base' (Prince \& Smolensky 1993). It can be established, however, that the results obtained via no-disagreement constraints are consistent with assuming unconstrained inputs. Whether inputs are fully specified or underspecified to some degree, whether features are monovalent or binary, whether features are free or linked - such variables will affect the details of the analysis but not the basic effect of nodisagreement constraints. For concreteness, I will assume representations in which outputs are fully specified for harmonic features. Where the harmonic value for a morpheme is entirely predictable from its context, I will assume an input that is unspecified for the harmonic feature.
} 
By removing the identity requirement between the two elements assessed by this constraint, the OCP becomes just one type of sequential prohibition, with proximity and similarity conditions holding of all such constraints.

(6) Sequential prohibitions: *X...Y: A sequence of X, Y on a tier is prohibited
OCP: $\mathrm{X}=\mathrm{Y}$
Harmony via No-Disagreement: $X \neq Y$

I propose that this class of sequential prohibitions applies to sequences of elements within tiers (Sagey 1986, etc.). Hence an ATR specification cannot be in sequence with another ATR specification (the OCP) nor can it be in sequence with an RTR specification (deriving harmony); a NASAL specification cannot be in sequence with another NASAL specification (the OCP) nor can it be in sequence with an ORAL specification; and so on. Just as the OCP holds more strongly of elements that are close together, so is harmony more rigorously enforced between elements that are close to each other. Just as the OCP holds more strongly between segments sharing multiple features, so does harmony apply more strongly in such cases of shared features.

A sample of the similarities between the OCP and harmony with respect to proximity are sketched in (7), with OCP examples cited from Suzuki (1998).

\begin{tabular}{|l|l|l|l|l|}
\cline { 2 - 5 } \multicolumn{1}{l|}{ (7) Proximity } & $X=Y$ & Example & $X \neq Y$ & Example \\
\hline Close & $* \mathrm{XX}$ & Ainu rhotics & ${ }^{*} \mathrm{XY}$ & $\begin{array}{l}\text { Local nasal } \\
\text { assimilation }\end{array}$ \\
\hline Medium & $* \mathrm{X}-\mathrm{C}_{0}-\mathrm{X}$ & $\begin{array}{l}\text { Kera low } \\
\text { vowels }\end{array}$ & ${ }^{*} \mathrm{X}-\mathrm{C}_{0}-\mathrm{Y}$ & $\begin{array}{l}\text { ATR harmony with } \\
\text { opacity }\end{array}$ \\
\hline Distant & $* \mathrm{X}-\infty-\mathrm{X}$ & $\begin{array}{l}\text { Japanese: } \\
\text { Lyman's Law }\end{array}$ & ${ }^{*} \mathrm{X}-\infty-\mathrm{Y}$ & $\begin{array}{l}\text { ATR harmony with } \\
\text { transparency }\end{array}$ \\
\hline
\end{tabular}

In the following sections, I argue for the no-disagreement approach to harmony while presenting cases illustrating different properties of the proposal. To begin with, I compare examples of opacity and transparency contrasting two dialects of Yoruba. In spite of the considerable attention that the opacity/transparency distinction has received in the literature, a reexamination of the question seems warranted. While it is not within the scope of this paper to examine previous approaches in any detail, ${ }^{7}$ the proposal here falls into the class where opacity vs. transparency is directly encoded: it falls out directly from the

\footnotetext{
${ }^{7}$ Opacity may be distinguished from transparency both directly and indirectly. A sample of the direct approaches includes distinctions in nule formulation (strictly local vs. optionally nonlocal) (Jensen 1974), the presence vs. absence of a blocking autosegment (Clements 1981), the selection of a harmonic value that matches/fails to match the value of the transparent class (Goldsmith 1985), the definition of alignment constraints (Pulleyblank 1996, Orie 2001). Various approaches have also been proposed that involve mediated reference to the neutral class - see discussion below. For example, harmony may apply to all segments but be followed by a rule of absolute neutralization (Lightner 1965), the optimal candidate may be 'sympathetic' to a fully harmonic candidate (McCarthy 1999), or 'targeted' constraints may be postulated (Baković \& Wilson 2001).
} 
ranking of constraints, with no postulation of abstract stages or representations.

\section{Opacity vs. Transparency: Qyo Yoruba vs. Ifẹ Yoruba}

Standard Yoruba has seven oral vowels $\{i, e, \varepsilon, a, o, o, u\}$ and exhibits a pattern of tongue root harmony involving opacity of the consistently advanced high vowels (Archangeli \& Pulleyblank 1989, 1994). Orie (2001, to appear) examines two dialects of Yoruba, Oyo and Ife. She demonstrates that Oyo exhibits a pattern extremely close to that of the standard language, while Ife differs markedly in that high vowels are transparent rather than opaque.

In both Oyọ and Ife, sequences of mid vowels must agree in their specification for tongue root advancement/retraction.

(8) Oyo Yoruba

oko farm okọ

òkè hill ọ̀kẹ́

ehoro rabbit opolo brain

ekòló earth- ẹ̀rẹ̀kẹ́ cheek

\section{Ife Yoruba}

$\begin{array}{llll}\text { oko } & \text { farm } & \text { ọkọ } & \text { husband } \\ \text { òye } & \text { proverb } & \text { ẹ̀dọ̀ } & \text { liver } \\ \text { ehoro } & \text { rabbit } & \text { ộrọ̀rọ̀ } & \text { type of bag } \\ \text { ògèdè } & \text { incanta- } & \text { ọ̣gẹ̀dẹ̀ } & \text { banana, } \\ & \text { tions } & & \text { plantain }\end{array}$

Such harmonic agreement results from an analysis largely analogous to that of Degema given in $\S 1$. One crucial difference, which will be motivated below, is that disharmony can be forced by the need to maintain root RTR specifications while satisfying substantive constraints on retraction and advancement.

(9) $[\text { MAXRTR }]_{\text {Root }}>>*$ ATR-C $0-$ RTR, ${ }^{*}$ RTR-C 0 - $\underline{\text { ATR }}>>[\text { MAXATR }]_{\text {Root }}$

For roots containing mid vowels, the effect of this ranking is full harmony. Moreover, because faithfulness to RTR outranks faithfulness to ATR, harmony initiated by a lexically specified RTR value will be achieved at the expense of any specified ATR value (cf. Archangeli \& Pulleyblank 1989). I illustrate this by an example, /ogede/, where I have arbitrarily assumed that the first two vowels are retracted in the input while the final vowel is advanced.

\begin{tabular}{|c|c|c|c|c|}
\hline (10)/ogede/ & {$[\text { MAXRTR }]_{R I}$} & ${ }^{*} \mathrm{ATR}-\mathrm{C}_{0}-\mathrm{RTR}$ & ${ }^{*} \mathrm{RTR}-\mathrm{C}_{0}-\underline{\underline{\mathrm{ATR}}}$ & {$[\text { MAXATR }]_{R T}$} \\
\hline [ogede] & & & *! & \\
\hline [ogede] & & & $* !$ & \\
\hline [ogede] & $* !$ & & & \\
\hline $\mathrm{d} \&[\mathrm{og} \varepsilon \mathrm{d} \varepsilon]$ & & & & * \\
\hline
\end{tabular}

The specific cases of interest for the analysis of neutrality are high vowels. Unlike their mid vowel counterparts, high vowels show a single value for the tongue root, namely advancement (Archangeli \& Pulleyblank 1989, 1994).

(11) *HI/RTR: A high vowel must be advanced, not retracted.

To absolutely rule out high retracted vowels, ${ }^{*} \mathrm{HI} / \mathrm{RTR}$ must outrank $[\mathrm{MAXRTR}]_{\mathrm{R} \text {; }}$; 
${ }^{*} \mathrm{HI} / \mathrm{RTR}$ must also outrank the harmonic constraint * ${ }^{\text {ATR }}-\mathrm{C}_{0}$ - RTR since harmony is not enforced following high vowels (on mid-high sequences, see below).

$\begin{array}{lllll}\text { Oyọ Yoruba \& } & \text { igbe } & \text { noise } & \text { ìgbẹ́ } & \text { excrement } \\ \text { Ifẹ Yoruba } & \text { igbó } & \text { bush } & \text { ilẹ̣ } & \text { ground } \\ & \text { eruku } & \text { dust } & \text { itộ } & \text { saliva } \\ & \text { ìrèké } & \text { sugarcane } & \text { ìọ̣lẹe } & \text { evening }\end{array}$

The tableau in (13) shows how surface disharmony can result from the appearance of a high vowel in a form with a lexical RTR specification. Whether the high vowel is underlyingly specified as ATR, as in (13), or underlyingly unspecified for a tongue root value, this does not affect the outcome.

\begin{tabular}{|c|c|c|c|c|c|c|}
\hline (13) & Aigbél & ${ }^{*} \mathrm{HI} / \mathrm{RTR}$ & {$[\text { MAXRTR }]_{\mathrm{RT}}$} & ${ }^{*} \underline{\underline{A}-\mathrm{C}_{0}-\mathrm{R}}$ & ${ }^{*} \mathrm{R}-\mathrm{C}_{0}-\underline{\underline{\mathrm{A}}}$ & {$[\mathrm{MAXATR}]_{\mathrm{RT}}$} \\
\hline a. 1 & [igbe] & & & $*$ & & \\
\hline b. & [igbe] & $* !$ & & & & * \\
\hline c. & [igbe] & & $* !$ & & & \\
\hline
\end{tabular}

Of interest for neutrality are cases where a high vowel appears flanked by mid vowels. One option for such words should be to have all vowels advanced, the result with inputs with no RTR specifications. Such words exist in both dialects.

$\begin{array}{lll}\text { Oyyọ Yoruba \& } & \text { ògùrò } & \text { stick for stirring } \\ \text { Ifẹ Yoruba } & \text { eúrò } & \text { bitter leaf } \\ & \text { oríwo } & \text { boil, tumor } \\ & \text { èbúté } & \text { harbour }\end{array}$

Of more interest are cases discussed by Orie where a mid-high-mid sequence involves retraction. In Oyo, as in Standard Yoruba, only the final mid vowel can be retracted. Ife shows a different pattern, with the initial and final mid vowels systematically harmonizing - although the intervening high vowel is unaffected.

\begin{tabular}{|c|c|c|c|c|c|}
\hline $\begin{array}{l}\text { Oyo Yoruba: } \\
\text { opacity }\end{array}$ & $\begin{array}{l}\text { eúrẹ́ } \\
\text { èlùbọ́ } \\
\text { òtítọ̣ } \\
\text { odíde }\end{array}$ & $\begin{array}{l}\text { goat } \\
\text { yam flour } \\
\text { truth } \\
\text { parrot }\end{array}$ & $\begin{array}{l}\text { Ife Yoruba: } \\
\text { transparency }\end{array}$ & $\begin{array}{l}\text { ẹúrée } \\
\text { ẹ̀lùbó } \\
\text { ọ̀títọ́ } \\
\text { odidẹ }\end{array}$ & $\begin{array}{l}\text { goat } \\
\text { yam flour } \\
\text { truth } \\
\text { parrot }\end{array}$ \\
\hline
\end{tabular}

The analysis presented above derives the opacity pattern of Oyọ.

\begin{tabular}{|c|c|c|c|c|c|}
\hline (16) & /EIUbo/ & ${ }^{*} \mathrm{H} / \mathrm{RTR}$ & {$[$ MAXRTR] ROOT } & ${ }^{*} \mathrm{RTR} \mathrm{C}_{0}-\mathrm{ATR}$ & ${ }^{*} \underline{\mathrm{ATR}}-\mathrm{C}_{0}-\mathrm{RTR}$ \\
\hline a. & elubo & & & & $*$ \\
\hline b. & clubo & *! & & & \\
\hline c. & Elubo & & & $* !$ & $*$ \\
\hline d. & elubo & & $* !$ & & \\
\hline e. & Elubo & & & $* !$ & \\
\hline
\end{tabular}




\section{Douglas Pulleyblank}

The high vowel cannot be advanced (16b); the lexically specified RTR value cannot be deleted (16d); an RTR specification must be as far to the right as possible $(16 \mathrm{c}, \mathrm{e})$. Note that [MAXRTR]Roor governs the retention of RTR but does not govern its location. Hence (16a) emerges as optimal no matter where an RTR value is specified in the input form, provided that the harmony constraints outrank constraints on location (for example, constraints of the 'MAXPATH' class (e.g. Pulleyblank 1996)). The ranking of *RTR- $\mathrm{C}_{0}$ - ATR over ${ }^{*}$ ATR- $\mathrm{C}_{0}-\mathrm{RTR}$ ensures the RTR feature occurs on the rightmost vowel (16a), not the leftmost vowel (16e). ${ }^{8}$

Since the analysis so far established derives opacity, some modification is needed to achieve the transparency observed in Ifẹ. Consider three instantiations of the generalized sequential prohibitions with respect to tongue root values:

(17) Proximal vs. distant sequential prohibitions

Close: $\quad$ *RTR ATR: An ATR segment may not be immediately preceded by RTR.

* ATR RTR: An ATR segment may not be immediately followed by RTR.

Medium: *RTR- $\mathrm{C}_{0}$-ATR: Ignoring consonants, an ATR segment may not be immediately preceded by RTR.

* ATR- $\mathrm{C}_{0}$-RTR: Ignoring consonants, an ATR segment may not be immediately followed by RTR.

Distant: *RTR- $\infty$-ATR: An ATR segment may not be preceded by RTR.

*ATR- $\infty$-RTR: An ATR segment may not be followed by RTR.

In its most local manifestation, the sequential prohibition would disallow any immediately adjacent sequence of differing tongue root specifications (relevant data will be discussed below). In its medium distance form, these prohibitions derive the pattern of opacity seen in Oyọ. I propose that the extension of the sequential prohibition to long-distance environments is the crucial innovation required to derive transparency of the type seen in Ife.

Consider a tableau for Ife - like (16) but with distant prohibition constraints:

\begin{tabular}{|c|c|c|c|c|c|}
\hline (18) & /ElUbo/ & ${ }^{*} \mathrm{HI} / \mathrm{RTR}$ & {$[\text { MAXRTR] }]_{R T}$} & *ATR- $\infty$-RTR & ${ }^{*} \mathrm{RTR}-\infty-\mathrm{ATR}$ \\
\hline a. & elubo & & & $* * !$ & \\
\hline b. & Elubo & $* !$ & & & \\
\hline c.\$ & Elubo & & & * & * \\
\hline d. & elubo & & *! & & \\
\hline
\end{tabular}

The medium distance no-disagreement constraint ${ }^{*}$ ATR- $\mathrm{C}_{0}-\mathrm{RTR}$ assigns exactly one violation to elubo in (16): two ATR segments precede the final RTR segment

\footnotetext{
${ }^{8}$ Two types of candidates should also be mentioned. First, gapped representations must be ruled out: a feature cannot link to two anchors while skipping an intervening anchor. I assume that this is due to the universal ill-formedness of a gapped representation (Archangeli \& Pulleyblank 1994, Pulleyblank 1996, Gafos 1996, Ní Chíosáin \& Padgett 1997) although it could also be achieved here by a 'NoGap' constraint (Itô, Mester \& Padgett 1995). Second, given the high ranking of [MAXRTR $]_{\text {Root }}$, it is also important that the OCP on RTR (*RTR- $\infty-R T R$ ) outrank root faithfulness. This prevents a form like [elubo] from being optimal for an input form having two RTR values.
} 
but only the medial vowel is in the local relation required to violate the constraint. In contrast, the distant formulation of *ATR- $\infty$-RTR is violated twice by elubo (18a): each ATR vowel is followed (locally or at a distance) by an RTR vowel. By

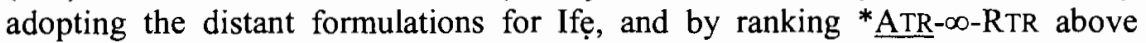
${ }^{*}$ RTR- $\infty$ - $\mathrm{ATR}$, the transparent candidate in $(18 \mathrm{c})$ is correctly assessed as optimal.

A problem emerges, however. In order for $(18 \mathrm{c})$ to be optimal, it is crucial that

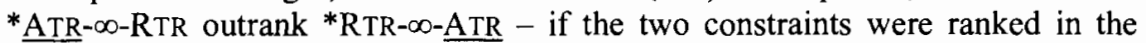
opposite order, then elubo (18a) would win over elubo (18c). The problem is that this ranking would actually evaluate *elubo as optimal (a candidate not included in (18)). Compare the tableau for Oyo in (16) where by ranking *RTR- $\infty$-ATR over

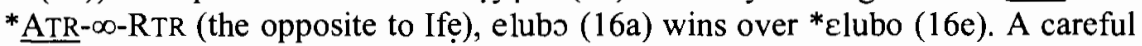
consideration of the two constraint rankings shows that one ranking will prefer the

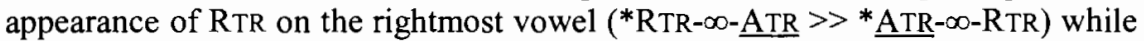
the other ranking ( $\left.{ }^{*} \underline{\mathrm{ATR}}-\infty-\mathrm{RTR} \gg{ }^{*} \mathrm{RTR}-\infty-\underline{\mathrm{ATR}}\right)$ prefers $\mathrm{RTR}$ on the leftmost vowel. Neither ranking derives transparency!

A consideration of this type of case reveals an interesting property of the proposed analysis of transparency. By themselves, a ranked pair of distant nodisagreement constraints will simply produce edge-orientation to the left or the right. To achieve transparency, either an additional constraint is needed or a restriction on the effect of the prohibition on RTR values preceding ATR values. For Ife, I propose a constraint on edge-anchoring: ${ }^{9}$

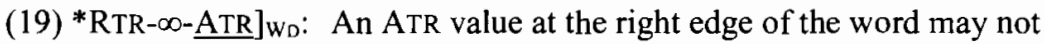
follow RTR.

This constraint rules out candidates like (20c) with a single RTR specification at the left edge of a word. The optimal candidate is the transparency candidate (20b).

\begin{tabular}{|c|c|c|c|c|c|}
\hline (20) /ElUbs/ & ${ }^{*} \mathrm{HI} / \mathrm{RTR}$ & 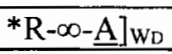 & {$[\text { MAXRTR }]_{\mathrm{RT}}$} & ${ }^{*} \mathrm{~A}-\infty-\mathrm{R}$ & $* \mathrm{R}-\infty-\mathrm{A}$ \\
\hline [elubo] & & & & $* * !$ & \\
\hline b. [Elubo] & & & & * & * \\
\hline [Elubo] & & $* !$ & & & ** \\
\hline
\end{tabular}

Postulating an edge-orientation constraint makes an immediate prediction for Ifẹ that is borne out. Compare the Oyọ and Ife forms in (21) which involve mid vowels before a string of one or more word-final high vowels (Orie to appear).

\footnotetext{
${ }^{9}$ Low vowels require a slight modification of this constraint since both $[\mathrm{aCe} / \mathrm{o}]$ and $[\mathrm{aC} \varepsilon / 0]$ patterns are possible. Such patterns indicate that the full form of the edge anchoring constraint is ${ }^{*}$ RTR/NONLo- $\infty-$ ATR/NONLO] WD $_{\mathrm{D}}$. The addition of the nonlow restriction falls into the class where a no-disagreement constraint applies more strongly between segments that share features. Since all ATR vowels are nonlow, the condition applies to vowels sharing the property of being nonlow.
} 


$\begin{array}{llllll}\text { Oyọ Yoruba: } & \text { ẹbí } & \text { family } & \text { Ife Yoruba: } & \text { ebí } & \text { family } \\ \text { pre-high } & \text { è̀ù̀ } & \text { fear } & \text { pre-high } & \text { èrù } & \text { fear } \\ \text { retraction } & \text { è̀wù } & \text { clothing } & \text { retraction } & \text { èwù } & \text { clothing } \\ \text { possible } & \text { ẹ̀bùnú } & \text { shortcut } & \text { not possible } & \text { èbùrú } & \text { shortcut }\end{array}$

As discussed by Orie, retraction is possible before a high vowel in Oyọ:

\begin{tabular}{|c|c|c|c|c|c|}
\hline$(22)$ & /عbUrU/ & ${ }^{*} \mathrm{HI} / \mathrm{RTR}$ & {$[\text { MAXRTR }]_{\text {ROOT }}$} & $* \mathrm{RTR}-\mathrm{C}_{0}-\mathrm{ATR}$ & ${ }^{*} \mathrm{ATR}-\mathrm{C}_{0}-\mathrm{RTR}$ \\
\hline a. & [eburu] & & & * & \\
\hline b. & [Eburu] & $* ! *$ & & & \\
\hline c. & [eburu] & & *! & & \\
\hline
\end{tabular}

The cognate forms in Ife, however, show advanced vowels before the high vowel string: retraction of mid vowels before a word-final high vowel is systematically excluded. This result is predicted by a constraint including the edge-orientation constraint. Consider the optimal output in Ife, assuming a mid-high sequence with retraction underlyingly, that is, exactly the input form just seen for Oyo.

\begin{tabular}{|c|c|c|c|c|c|}
\hline (23) / $\mathrm{ebUrU/}$ & ${ }^{*} \mathrm{HI} / \mathrm{RTR}$ & $\left.{ }^{*} \mathrm{R}-\infty-\underline{\mathrm{A}}\right]_{\mathrm{WD}}$ & {$[\text { MAXRTR }]_{\text {RoOT }}$} & ${ }^{*} \underline{A}-\infty-R$ & ${ }^{*} \mathrm{R}-\infty-\underline{\mathrm{A}}$ \\
\hline a. [Eburu] & & $* !$ & & & ** \\
\hline [Eburu] & $*$ ** & & & & \\
\hline c. $\$$ eburu] & & & * & & \\
\hline
\end{tabular}

Whether or not a 'mid...high]' form includes an RTR specification in its input representation, the optimal surface form in Ife will have all vowels advanced.

Does the no-disagreement approach makes transparency too easy to achieve? Assuming that opacity is more common cross-linguistically than transparency, the theory must provide an explanation for this skewing. In fact, numerous factors work against transparency. First, representations with transparency invariably violate the OCP. As such, high ranking of the OCP would produce opacity, not transparency. Similarly, transparency can require the appearance in the output of one or more harmonic feature values not present in the input - that is, DEP can be violated. Hence transparency is only possible if DEP is ranked sufficiently low (Pulleyblank 1996). Also working against transparency, the no-disagreement constraint must be set for its 'distant' value. More local instantiations of nodisagreement derive opacity, not transparency. Independent of the issue of transparency vs. opacity, it is clear that featural interaction is maximized in local environments rather than distant ones (Mohanan 1993, Suzuki 1998). A fourth factor working against transparency is factorial rigidity: while four permutations of the basic constraints Faith, ${ }^{*}$ ATR- $\infty$-RTR, and *RTR- $\infty$-ATR produce opacity, only the two rankings with faithfulness above both no-disagreement constraints can produce transparency. A final point concerns the need for edge orientation: even if the basic no-disagreement constraints are ranked appropriately, transparency is only possible if some additional consideration such as edge orientation plays a role. Overall, deriving transparency via no-disagreement 
constraints is straightforward, but limited in its potential by numerous independent factors.

\section{Edge-conditioned harmony with transparency of undergoers}

There exists a class of harmonic cases where edge orientation plays a fundamental role: harmony only applies from a trigger at the edge of a domain. These cases are of particular interest when they involve transparency since the transparent segments are perfectly eligible recipients of the harmonic feature. Consider the case of C'Lela (Dettweiler 2000), a Benue-Congo language of Nigeria.

C'Lela exhibits an eight-vowel inventory with 3 high and 5 nonhigh vowels: $\{\mathrm{i}, \mathrm{i}, \mathrm{u}, \mathrm{e}, \boldsymbol{\varepsilon}, \mathrm{a}, \mathrm{\supset}, \mathrm{o}\}$. Harmony is with respect to height, hence roots may exist with high vowels only or with nonhigh vowels only. ${ }^{10}$

$\begin{array}{llllll}\text { a. } & \mathrm{d}^{2} \text { tindi } & \text { nest } & \text { g. } & \text { kwesa } & \text { show } \\ \text { b. } & \mathrm{c}^{2} \text { rini } & \text { charcoal } & \text { h. } & \text { 'ddakso } & \text { palm (of hand) } \\ \text { c. } & \text { irmi } & \text { man } & \text { i. } & \text { c }^{2} \text { gyombo } & \text { eyebrows } \\ \text { d. } & \text { kumu } & \text { get } & \text { j. } & \text { soma } & \text { run } \\ \text { e. } & k^{2} \text { piru } & \text { flower } & \text { k. } & \text { d}^{2} \text { veso } & \text { broom } \\ \text { f. } & \text { dwiri } & \text { hyena } & \text { l. } & \text { s?ava } & \text { tongs }\end{array}$

In addition to distributional patterns such as seen in (24), affixes such as the pronominal suffixes of (25) provide evidence of height-based alternations: the suffixes are high after a high root and nonhigh after a nonhigh root.
a. $-\mathrm{mi} / \mathrm{me}$
$l^{s t} s g \quad$ in-mi
my mother
cet-me my father
b. $-\mathrm{vu} / \mathrm{vo}$
$2^{\text {nd }} s g$ in-vu
your mother
cet-vo
your father
c. $-\mathrm{u} / \mathrm{o}$
$3^{\text {rd }} s g$
hin-u his sibling
cet-o
her father
waar-o his child

A consideration of suffixal behavior provides evidence that the alternating vowels are underlyingly high. The direct object pronouns of (26) fall into two classes: (i) forms alternating according to the height-based pattern, (ii) forms exhibiting a height value unconditioned by the root to which it attaches.

(26) a. $\mathrm{mi} / \mathrm{me} \quad I^{s t} \mathrm{sg}$

\begin{tabular}{|c|}
\hline 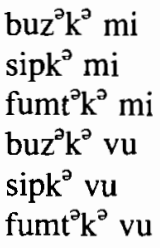 \\
\hline
\end{tabular}

chased/bit me grabbed/indicated me

b. $\mathrm{vu} / \mathrm{vo} \quad 2^{\text {nd }} \mathrm{sg}$ pulled/released me chased/bit you grabbed/indicated you pulled/released you

\footnotetext{
${ }^{10}$ The raised schwa represents a vowel Dettweiler $(2000 ; 4)$ describes as "a nonphonemic vowel which serves as a short transition between certain occurrences of consonants in clusters." This brief vowel often appears to be "an echo of the full vowel preceding the consonant." If this vowel is to be represented phonologically, I assume its representation is a featureless mora.
} 


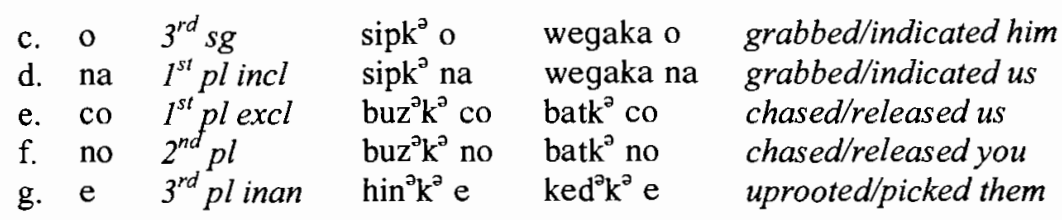

The generalization is that nonalternating suffixes are nonhigh. ${ }^{11}$ This suggests that the alternating class corresponds to the 'high' class: an underlyingly high vowel lowers to mid after a nonhigh vowel but remains high after a high vowel.

The basic analysis of C'Lela depends on two no-disagreement constraints. Since a high-nonhigh sequence is impossible within a root, but tolerated between a root and a suffix, a constraint ruling out such a sequence must only apply root internally. Since a nonhigh-high sequence is ruled out generally, a constraint governing such a sequence must apply within the broader domain of the word.

$(27)^{*}\left[\ldots \underline{\text { HI }}-\mathrm{C}_{0} \text {-NoNHI.... }\right]_{\text {Root }}$ : Within a root, a high vowel may not be followed by a nonhigh vowel (ignoring consonants) $\left(*\left[\ldots \underline{\mathrm{I}}-\mathrm{C}_{0}-\mathrm{E} \ldots\right]_{\mathrm{Rt}}\right)$

*[...NONHI- $\infty-\underline{H} \mathrm{I}]$ word: $\quad$ A word-final high vowel may not be preceded by a nonhigh vowel $\left.\left({ }^{*} \mathrm{E}-\infty-\underline{\mathrm{I}}\right]_{\mathrm{Wd}}\right)$

The word-final restriction will be discussed shortly. The harmonic conditions override faithfulness so they must outrank conditions on the retention of height. I assume root and word domain faithfulness for height analogous to the constraints given for the tongue root in (3), ranked below the harmony constraints. ${ }^{12}$

These constraints rule out height disagreement within the root domain.

\begin{tabular}{|c|c|c|c|c|c|c|c|}
\hline \multirow[t]{2}{*}{ (28) } & \multirow[t]{2}{*}{ /suma/ } & \multirow[t]{2}{*}{$*\left[\ldots \underline{\mathrm{I}}-\mathrm{C}_{0}-\mathrm{E} \ldots\right]_{\mathrm{Rt}}$} & \multirow[t]{2}{*}{$\left.{ }^{*} E-\infty-\underline{I}\right] w d$} & \multicolumn{2}{|c|}{$[\mathrm{MAX}]_{\mathrm{ROOT}}$} & \multicolumn{2}{|c|}{$[\mathrm{MAX}]_{\text {WORD }}$} \\
\hline & & & & NONHI & $\mathrm{HI}$ & NONHI & $\mathrm{Hl}$ \\
\hline a. & [suma] & $* !$ & & & & & \\
\hline b. & [soma] & & & & $*$ & & * \\
\hline c. $\$$ & [sumi] & & & $* !$ & & * & \\
\hline d. & [somi] & & $* !$ & * & * & * & * \\
\hline
\end{tabular}

For reasons that go beyond C'Lela, I assume that faithfulness to nonhigh values outranks faithfulness to high values (Howe \& Pulleyblank 2001), though I will not pursue this issue here. Tableau (28) illustrates the result with a high-nonhigh

\footnotetext{
${ }^{11}$ An apparent exception to this is the third person plural ni, e.g. fumt ${ }^{2} \mathrm{k}^{2} \mathrm{ni}$ 'pulled them', batk $\mathrm{k}^{2}$ i 'released them', which Dettweiler shows should be analyzed with an epenthetic high vowel. If ni has no vowel underlyingly, the generalization is that underlyingly high vowels alternate while nonhigh vowels do not. Epenthetic [i] can be exempted from the harmonic imperative by ranking the markedness conditions against the insertion of nonhigh vowel above harmony. If we assume a constraint prohibiting the epenthesis of a [-high] vowel (DEP $\mu[-$ hi $]$ ) and a second constraint prohibiting the epenthesis of a [+high] vowel (DEP $\mu[+$ hi]), then the high ranking of DEP $\mu[-h i]$ will prevent the epenthesis of a nonhigh vowel: DEP[-hi] $\gg$ DEP $[+h i], *[\ldots \text { NoNHI- } \infty-\mathrm{HI}]_{\text {Word. }}$.

$12[\mathrm{MAXNONHIGH} / \mathrm{HIGH}]_{\mathrm{ROOT} / \mathrm{WORD}}$ : Within the root/word, a NONHIGH/HIGH value in the input must correspond to a NONHIGH/HIGH value in the output.
} 
sequence; a comparable result would obtain with a nonhigh-high sequence.

Beyond the root, high-nonhigh and nonhigh-high sequences diverge in their properties. When a nonhigh suffix is attached to a high root, the root-internal prohibition of a high-nonhigh sequence is irrelevant because of its domain restriction and the prohibition of a nonhigh-high sequence is irrelevant because there is no nonhigh-high sequence. The result is therefore suffixal disharmony.

\begin{tabular}{|c|c|c|c|c|c|c|c|}
\hline \multirow[t]{2}{*}{ (29) } & \multirow[t]{2}{*}{$/ b^{2} \mathbf{z}^{\curvearrowright} \mathrm{co} /$} & \multirow[t]{2}{*}{$*\left[. \mathrm{I}-\mathrm{C}_{0}-\mathrm{E} .\right]_{\mathrm{Rt}}$} & \multirow[t]{2}{*}{$\left.{ }^{*} \mathrm{E}-\infty-\mathrm{I}\right]_{\mathrm{Wd}}$} & \multicolumn{2}{|c|}{$[\text { MAX }]_{\text {Root }}$} & \multicolumn{2}{|c|}{$[$ MAX] WORD } \\
\hline & & & & NONHI & HI & NONHI & HI \\
\hline a.d & {$\left[\left[\mathrm{buz}^{2} \mathrm{k}^{\partial}\right]_{\mathrm{Rt}} \mathrm{co}\right]$} & & & & & & \\
\hline b. & {$\left[\left[\mathrm{buz}^{2} \mathrm{k}^{2}\right]_{\mathrm{Rt}} \mathrm{cu}\right]$} & & & & & $* !$ & \\
\hline & {$\left[\left[\mathrm{boz}^{2} \mathrm{k}^{2}\right]_{\mathrm{Rt}} \mathrm{co}\right]$} & & & & $* !$ & & * \\
\hline
\end{tabular}

When a high suffix is attached to a nonhigh root, in contrast, the word-level prohibition of a nonhigh-high sequence eliminates the fully faithful candidate.

\begin{tabular}{|c|c|c|c|c|c|c|c|}
\hline \multirow[t]{2}{*}{ (30) } & \multirow[t]{2}{*}{ /wegaka vu/ } & \multirow[t]{2}{*}{${ }^{*}\left[. \mathrm{I}-\mathrm{C}_{0}-\mathrm{E} .\right]_{\mathrm{Rt}}$} & \multirow[t]{2}{*}{${ }^{* E-\infty}-[-I]_{W d}$} & \multicolumn{2}{|c|}{$[\mathrm{MAX}]_{\text {ROOT }}$} & \multicolumn{2}{|c|}{$[\mathrm{MAX}]_{\text {WORD }}$} \\
\hline & & & & NONHI & $\mathrm{HI}$ & NONHI & $\mathrm{HI}$ \\
\hline a. & {$\left[[\text { wegaka }]_{\mathrm{Rt}} \mathrm{vu}\right]$} & & $*$ *** & & & & \\
\hline b. & {$\left[[\text { wegaka }]_{\mathrm{Rt}}\right.$ vo $]$} & & & & & & $*$ \\
\hline c. & {$\left[[\text { wigiki }]_{\mathrm{Rt}} \mathrm{vu}\right]$} & & & $* ! * *$ & & $* * *$ & \\
\hline
\end{tabular}

[MAXNONHI $]_{\text {Root }}$ selects the harmonic candidate with altered suffixal height (30b) rather than the alternative candidate modifying root values $(30 \mathrm{c})$.

So far, all vowels within a root agree for height, and high vowel suffixes harmonize. Cases with multiple suffixes, however, show an interesting restriction on the applicability of harmony: the word-final vowel is subject to harmony, while nonfinal high suffix vowels are neutral and transparent. Consider (31) where the right-hand column shows that the class markers - $\mathrm{i} /$-e $\&$ - $\mathrm{u} /$-o harmonize when they are word-final ${ }^{13}$ and the left-hand column shows that these morphemes are high when nonfinal $(\mathrm{CM}=$ class marker; $\mathrm{ADJM}=$ adjectival suffix $){ }^{14}$

${ }^{13}$ As seen above, epenthetic vowels do not harmonize even when word-final. Hence the final epenthetic vowels in i-po-ji ' $\mathrm{CM}$-new- $\mathrm{CM}^{\prime}$ ' and $\mathrm{u}-\mathrm{s}$ "a-wi ' $\mathrm{CM}$-big- $\mathrm{CM}^{\mathrm{\prime}}$ ' are high even though the roots are nonhigh. The final vowel can be seen to be epenthetic by comparing the forms that include adjectival suffixes: i-po-i-ne 'CM-new-CM-ADJM', u-s"a-u-ne 'CM-big-CM-ADJM'.

${ }^{14}$ The word-final adjectival suffix (-ni/-ne) harmonizes with the root as expected, appearing as -ni after a high root $(0 \mathrm{a}-\mathrm{c})$ and as - ne after a nonhigh root $(0 \mathrm{~d}-\mathrm{f})$. 

a. i-zis-i-ni
CM-long-CM-ADJM
i-zis-i
CM-long- $C M$
b. u-pus-u-ni
$C M$-white-CM-ADJM
u-pus-u
CM-white-CM
c. u-rim-u-ni
[rim-u-ni]
CM-black-CM-ADJM
u-rim-u
[rim-u]
CM-black-CM
d. i-rek-i-ne
CM-small-CM-ADJM
i-rek-e
CM-small-CM
e. u-gjoz-u-ne
CM-red-CM-ADJM
u-g joz-o $^{\text {jo }}$
CM-red-CM
f. u-rek-u-ne
CM-small-CM-ADJM
u-rek-o
[rek-o]
CM-small-CM

The fact that the same morphemes harmonize word-finally but fail to harmonize medially indicates that failure to harmonize must be attributed to the morphemes' position in the word, not to some idiosyncrasy of the morphemes in question.

This conclusion is supported by the behavior of a polysyllabic suffix like -ini/ine 'perfective aspect'. Within a morpheme, we see that the word-final vowel is subject to height harmony while the medial high vowel is neutral and transparent.

\begin{tabular}{llll} 
High root & a. & sip-ini & grap- $P E R F$ \\
& b. & buz-ini & chase- $P E R F$ \\
& c. & fumti-ini & pull-PERF \\
\hline Nonhigh root & d. & Ep-ine & bite- $P E R F$ \\
& e. & bat-ine & release- $P E R F$ \\
& f. & wega-ine & indicate- $P E R F$
\end{tabular}

One last class of cases to consider involves class markers that are not high. As expected, a nonhigh class marker itself is invariable: the only potentially relevant constraint would be the no-disagreement constraint prohibiting nonhigh vowels after high vowels, but that constraint is restricted to the root domain. Where alternations are expected is when a nonhigh class marker precedes a high suftix such as the adjectival marker. Irrespective of the root value in such a case, if the high suffix is word-final, the expectation is that the high suffix should surface as nonhigh after the nonhigh class marker. The examples in (33) confirm these predictions; compare these forms with those in (31) where the -ni/-ne suffix is high or nonhigh depending on the root to which it is attached.

\begin{tabular}{|c|c|c|c|c|c|c|}
\hline (33) & $\begin{array}{r}\text { High } \\
\text { root }\end{array}$ & $\begin{array}{l}\text { a. } \\
\text { b. }\end{array}$ & $\begin{array}{l}\text { a-rim-a-ne } \\
\text { a-zis-a-ne }\end{array}$ & $\begin{array}{l}C M \text {-black-CM-ADJM } \\
C M \text {-long-CM-ADJM }\end{array}$ & $\begin{array}{l}\text { a-rim-a } \\
\text { a-zis-a }\end{array}$ & $\begin{array}{l}C M \text {-black- } C M \\
C M \text {-long- } C M\end{array}$ \\
\hline \multirow{3}{*}{\multicolumn{2}{|c|}{$\begin{array}{r}\text { Nonhigh } \\
\text { root }\end{array}$}} & c. & a-rek-a-ne & CM-small-CM-ADJM & a-rek-a & all-CM \\
\hline & & d. & $a-g^{j} \partial z$ & $C M$-red-CM-ADJM & $a-g^{j} \partial z-a$ & $d-C M$ \\
\hline & & e. & a-s"a-a-ne & $C M$-big-CM-ADJM & $u-s^{w} a-n a$ & $C M$-big-CM \\
\hline
\end{tabular}

The cases involving sequences of suffixes are accounted for by the analysis presented for single suffixes. Consider examples where an underlyingly high class 
marker occurs in different positions in the word. In final position, the class marker will lower when following a nonhigh root: input /rek-u/gives output [rek-o]. Such an example is analogous to comparable cases seen above; see the tableau in (30). When the same suffix occurs medially, it will fail to harmonize:

\begin{tabular}{|c|c|c|c|c|c|c|}
\hline \multirow[t]{2}{*}{ (34) /rek-u-ni/ } & \multirow[t]{2}{*}{$\left.* \ldots I-C_{0}-E \ldots\right]_{\mathrm{Rt}}$} & \multirow[t]{2}{*}{$\left.{ }^{*} \mathrm{E}-\infty-\underline{\mathrm{I}}\right]_{\mathrm{Wd}}$} & \multicolumn{2}{|c|}{$[\mathrm{MAX}]_{\text {Root }}$} & \multicolumn{2}{|c|}{$[\text { MAX }]_{\text {WORD }}$} \\
\hline & & & NONHI & $\mathrm{HI}$ & NONHI & $\mathrm{HI}$ \\
\hline $\begin{array}{ll}\text { a. } & {\left[[\mathrm{rek}]_{\mathrm{Rt}} \mathrm{u}-\mathrm{ni}\right]}\end{array}$ & & $* !$ & & & & \\
\hline b. $\diamond\left[[\text { rek }]_{\mathrm{Rt}} \mathrm{u}-\mathrm{ne}\right]$ & & & & & & $*$ \\
\hline c. $\left[[\mathrm{rek}]_{\mathrm{Rt}} \mathrm{o}-\mathrm{ne}\right]$ & & & & & & $* * !$ \\
\hline $\begin{array}{ll}\text { d. } & {\left[[\text { rik }]_{\mathrm{Rt}} \mathrm{u}-\mathrm{ni}\right]}\end{array}$ & & & $* !$ & & * & \\
\hline
\end{tabular}

The crucial comparison is between rekune and rekone $(34 \mathrm{~b} / \mathrm{c})$. Both candidates satisfy $* \mathrm{NONHI}-\infty-\underline{\mathrm{HI}}]_{\mathrm{Wd}}$ because there is no word-final high vowel; both satisfy root-domain faithfulness. Distinguishing between the candidates is $[\mathrm{MAXHI}]_{\text {WORD }}$. While it is necessary to violate word-level faithfulness once in order to satisfy $\left.{ }^{*} \mathrm{NONH}-\infty-\mathrm{Hl}_{\mathrm{W}}\right]_{\mathrm{d}}$, the second violation of rekone $(34 \mathrm{c})$ is gratuitous: with the final vowel nonhigh, neither of the no-disagreement constraints forces the additional faithfulness violation that results from lowering of the penultimate vowel.

This pattern of transparency has significant implications. Medial vowels are transparent to harmony, but they are not incompatible with the harmonic feature. This makes the C'Lela patterns problematic for most accounts of transparency. In various instantiations, it is typical to define transparent segments through their incompatibility with the harmonic feature (Kiparsky 1981). This may be achieved by allowing a 'gapped' representation to result from the spreading of a feature over the incompatible segment (e.g. Vago 1988); it may be achieved by allowing the harmonic feature to duplicate itself as it skips the transparent segment (e.g. Archangeli \& Pulleyblank 1994, Pulleyblank 1996); it may be achieved through comparison of the winner (which respects the incompatibility) to a candidate that is fully harmonic (but violates the incompatibility) (e.g. sympathy theory (McCarthy 1999) and targeted constraints (Baković \& Wilson 2001)); it could be achieved through absolute neutralization (e.g. Lightner 1965). All such approaches to transparency depend on having a transparent class that is incompatible with the harmonic feature. Since C'Lela transparent segments exhibit no such incompatibility - that is, no feature such as backness or roundness makes $/ \mathbf{i} /$ or $/ \mathbf{u} /$ ineligible to receive a nonhigh feature - they cannot be accounted for by a theory of transparency that depends crucially on incompatibility.

\section{Conclusion and implications}

This paper addresses the multiplicity of drivers for harmonic behavior in the recent optimality literature by arguing that harmony results from languages attempting to minimize the resetting of articulators, by languages giving in to articulatory inertia. Formally, such inertia is encoded through 'no-disagreement' constraints. These constraints are close cousins to the OCP, with both types of 
constraints prohibiting sequences of elements, where the prohibitions are most rigorously enforced in local environments and between segments exhibiting shared features. The OCP becomes the logical extreme of a continuum defined by similarity, where the segments being compared are so similar as to be identical.

The implications of driving harmony by the prohibition of difference are numerous, and this paper focuses on implications for transparency. The essence of the proposal is twofold. First, violations of no-disagreement may be forced by a more highly ranked constraint requiring that some segment class have a particular value of the harmonic feature. Proposals basing neutrality on incompatibility have been instantiated in a wide variety of ways in both derivational and constraintbased theories of harmony. The second, more novel, proposal is that neutrality may result from inapplicability. No-disagreement may be defined contextually, with only appropriately positioned segments subject to the constraint; segments intervening between a contextually defined segment and some class of prohibited segments need not be incompatible with the harmonic value.

In closing, I note three additional implications of the no-disagreement approach to harmony, implications that space prevents me from addressing in this paper. First, it is possible to account for cases of incomplete harmony, that is, cases where the features harmonically assigned to some target do not match features of the source. When harmony and assimilation are by spreading, some feature or features of the harmonic source must necessarily be shared by the target output; when harmony is by no-disagreement, then cases involving values of a single feature will be comparable, but cases involving two or more features may result in the optimal harmonic output exhibiting some intermediate value between the prohibited segment and the harmonic source. An example is Setswana (Dichabe 1997; Khabanyane 1991, Clements 1991 on the closely related Sesotho) where harmony creates a three-way height distinction in high vowels on the surface where only a two-way distinction exists underlyingly. A second way in which the no-disagreement approach differs from conventional spreading or agreement analyses is in the explicit expectation that harmony will manifest itself more strongly among segments sharing features - a frequently observed property in harmony systems. To cite a single case involving the tongue root, Lango (Woock \& Noonan 1979, Noonan 1992, Smolensky 1993, Archangeli \& Pulleyblank 1994) shows a preference for harmony between segments sharing height features. A final point of interest is that vowel and consonant harmony can be unified. It has proven problematic to analyze both consonant harmony and vowel harmony by the same mechanism because of the typically local property of vowel harmony and the apparently nonlocal property of consonant harmony (cf. Gafos 1996). With harmony resulting from no-disagreement, both types of processes can be accounted for by the same constraint type. 


\section{References}

Akinlabi, Akinbiyi. 1996. Featural affixation. Journal of Linguistics 32: 239-289. Archangeli, Diana \& Douglas Pulleyblank. 1989. Yoruba vowel harmony. Linguistic Inquiry 20: 173-217.

Archangeli, Diana \& Douglas Pulleyblank. 1994. Grounded Phonology. MIT Press, Cambridge, MA.

Archangeli, Diana \& Douglas Pulleyblank. To appear. Kinande vowel harmony: domains, grounded conditions, and one-sided alignment. Phonology.

Baković, Eric. 2000. Harmony, Dominance and Control. Ph.D. dissertation, Rutgers University.

Baković, Eric and Colin Wilson. 2001. Transparency, strict locality, and targeted constraints. Proceedings of WCCFL 19. Cascadilla Press, Somerville.

Beckman, Jill. 1995. Shona height harmony: markedness and positional identity. In J. Beckman, L. Walsh Dickey \& S. Urbanczyk (eds.) Papers in Optimality Theory, 53-75. Amherst: Univ. of Massachusetts Occasional Papers 18.

Clements, G.N. 1981. Akan vowel harmony: a nonlinear analysis. In G.N. Clements (ed.) Harvard Studies in Phonology 2: 108-177. Department of Linguistics, Harvard University.

Clements, G.N. 1991. Vowel height assimilation in Bantu languages. Working Papers of the Cornell Phonetics Laboratory 5: 37-76.

Cole, Jennifer \& Charles W. Kisseberth. 1994. An Optimal Domains theory of harmony. Cognitive Science Tech. Report UIUC-BI-CS-94-02, U. of Illinois.

Dettweiler, Stephen H. 2000. Vowel harmony and neutral vowels in C'Lela. The Journal of West African Languages 28: 3-18.

Dichabe, Seipati Bernice. 1997. Advanced tongue root harmony in Setswana. M.A. thesis, University of Ottawa.

Elugbe, Ben O. 1984. Morphology of the gerund in Degema and its reconstruction in Proto- Edoid. Studies in African Linguistics 15: 77-89.

Gafos, Adamantios. 1996. The Articulatory Basis of Locality in Phonology. Ph.D. dissertation, The Johns Hopkins University.

Goldsmith, John. 1985. Vowel harmony in Khalkha Mongolian, Yaka, Finnish and Hungarian. Phonology Yearbook 2: 253-275.

Hansson, Gunnar. 2001. Theoretical and Typological Issues in Consonant Harmony. Ph.D. dissertation, University of California, Berkeley.

Hansson, Gunnar. 2002. Absolute directionality in output-oriented phonology. Paper presented at the University of British Columbia.

Howe, Darin \& Douglas Pulleyblank. 2001. Harmony as faithfulness. Ms. University of Calgary \& University of British Columbia.

Itô, Junko, Armin Mester \& Jaye Padgett. 1995. Licensing and underspecifiration in Optimality Theory. Linguistic Inquiry 26: 571-613.

Jensen, John. 1974. A constraint on variables in phonology. Language 50: 675-86. Kari, Ethelbert E. 1995. The Structure of the Degema Verb. M.A. thesis, University of Port Harcourt. 
Kari, Ethelbert E. 1997. Degema. Lincom Europa, München-Newcastle.

Khabanyane, Khathatso Evelyn. 1991. The five phonemic vowel heights of Southern Sotho: an acoustic and phonological analysis. Working Papers of the Cornell Phonetics Laboratory 5: 1-36.

Kiparsky, Paul. 1981. Vowel harmony. Ms., MIT.

Kirchner, Robert. 1993. Turkish vowel disharmony in Optimality Theory. Paper presented at the Rutgers Optimality Workshop \#1, Rutgers University.

Lightner, Theodore. 1965. On the description of vowel and consonant harmony. Word 21: 244-250.

McCarthy, John. 1986. OCP effects: gemination and antigemination. Linguistic Inquiry 17: 207-63.

McCarthy, John. 1999. Sympathy \& phonological opacity. Phonology 16: 331-99. McCarthy, John \& Alan Prince. 1995. Faithfulness and reduplicative identity. In Jill N. Beckman, Laura Walsh Dickey, \& Suzanne Urbanczyk (eds.) Papers in Optimality Theory, Univ. of Massachusetts Occasional Papers 18: 249-384.

Mohanan, K.P. 1993. Fields of attraction in phonology. In John Goldsmith (ed.)

The Last Phonological Rule: Reflections on Constraints and Derivations. Chicago University Press, Chicago.

Ní Chiosáin, Máire \& Jaye Padgett. 1997. Markedness, segment realization, and locality in spreading. Report LRC-97-01, Linguistic Research Center, UCSC.

Noonan, Michael. 1992. A Grammar of Lango. Mouton de Gruyter, Berlin.

Orie, Olanike Ola. 2001. An alignment-based account of vowel harmony in Ifẹ Yoruba. Journal of African Languages and Linguistics 22: 117-143.

Orie, Olanike Ola. To appear. Two harmony theories and high vowel patterns in four Benue-Congo harmony systems. The Linguistic Review.

Prince, Alan \& Paul Smolensky. 1993. Optimality Theory: constraint interaction and satisfaction. Ms. Rutgers University \& University of Colorado at Boulder. Pulleyblank, Douglas. 1996. Neutral vowels in Optimality Theory: a comparison of Yoruba and Wolof. Canadian Journal of Linguistics 41: 295-347.

Pulleyblank, Douglas, Ping Jiang-King, Myles Leitch, \& Ọlanikẹ Ọla. 1995.

Typological variation through constraint rankings: low vowels in tongue root harmony. Proceedings of South Western Optimality Theory Workshop. The University of Arizona Coyote Papers, 184-208.

Sagey, Elizabeth. 1986. The Representation of Features and Relations in Nonlinear Phonology. Ph.D. diss., MIT. [Published 1990, Garland, New York] Smolensky, Paul. 1993. Harmony, markedness, and phonological activity. Paper presented at the Rutgers Optimality Workshop \#1, Rutgers University.

Suzuki, Keiichiro. 1998. A Typological Investigation of Dissimilation. Ph.D. dissertation, University of Arizona.

Vago, Robert. 1988. Underspecification in the height harmony system of Pasiego. Phonology 5: 343-362.

Walker, Rachel. 1998. Nasalization, Neutral Segments, and Opacity Effects. Ph.D. dissertation, University of California, Santa Cruz. 
Harmony Drivers: No Disagreement Allowed

Woock, E.B. \& Michael Noonan. 1979. Vowel harmony in Lango. Chicago Linguistic Society 15: 20-29.

Department of Linguistics

University of British Columbia

Vancouver, BC, Canada V6T 1Z1

Douglas.Pulleyblank@UBC.ca 